\title{
Complex interaction of obesity, intentional weight loss and heart failure: a systematic review and meta- analysis
}

\author{
Rajiv Mahajan (1) 1,2 Michael Stokes, ${ }^{1,3}$ Adrian Elliott, ${ }^{1,3}$ Dian A Munawar, ${ }^{1,3}$ \\ Kashif B Khokhar, ${ }^{1,3}$ Anand Thiyagarajah, ${ }^{1,3}$ Jeroen Hendriks $\odot 1,{ }^{1,3}$ Dominik Linz, ${ }^{1,3}$ \\ Celine Gallagher, ${ }^{1,3}$ David Kaye, ${ }^{4,5}$ Dennis Lau, ${ }^{1,3}$ Prashanthan Sanders (1) 1,3
}

- Additional material is published online only. To view please visit the journal online (http://dx.doi.org/10.1136/ heartjnl-2019-314770).

${ }^{1}$ Centre for Heart Rhythm Disorders, University of Adelaide, Adelaide, South Australia, Australia

${ }^{2}$ Department of Cardiology, Lyell McEwin Hospital, Elizabeth Vale, South Australia, Australia ${ }^{3}$ Department of Cardiology, Royal Adelaide Hospital, Adelaide, South Australia, Australia

${ }^{4}$ Department of Cardiology, Alfred Hospital, Melbourne, Victoria, Australia

${ }^{5}$ Heart Research, Baker IDI Heart and Diabetes Institute, Melbourne, Victoria, Australia

\section{Correspondence to} Professor Prashanthan Sanders, Centre for Heart Rhythm Disorders, University of Adelaide, Adelaide;

prash.sanders@adelaide.edu.au

DL and PS contributed equally. RM and MS contributed equally.

Received 18 January 2019

Revised 27 May 2019

Accepted 24 June 2019

Published Online First

17 September 2019

\section{ABSTRACT}

Objective The aim of the meta-analysis was to determine the association of obesity and heart failure (HF) and the cardiac impact of intentional weight loss following bariatric surgery on cardiac structure and myocardial function in obese subjects.

Methods MEDLINE, Embase and Web of Science were searched up to 3 April 2018. Studies reporting association and prognostic impact of obesity in HF and the impact of intentional weight loss following bariatric surgery on cardiac structure and myocardial function in obesity were included in the meta-analysis.

Results 4959 citations were reviewed. After exclusions, 29 studies were analysed. A 'J curve' relationship was observed between body mass index (BMI) and risk of $\mathrm{HF}$ with maximum risk in the morbidly obese (1.73 (95\% Cl 1.30 to 2.31), $p<0.001, n=11$ ). Although 'obesity paradox' was observed for all-cause mortality, the overweight group was associated with lower cardiovascular (CV) mortality $(\mathrm{OR}=0.86(95 \% \mathrm{Cl} 0.79$ to $0.94), n=11$ ) with no significant differences across other BMI groups. Intentional weight loss induced by bariatric surgery in obese patients $(n=9)$ without established HF, atrial fibrillation or known coronary artery disease, was associated with a reduction in left ventricular mass index $(p<0.0001)$, improvement in left ventricular diastolic function ( $p \leq 0.0001)$ and a reduction in left atrial size $(p=0.02)$.

Conclusions Despite the increased risk of HF with obesity, an 'obesity paradox' is observed for all-cause mortality. However, the nadir for CV mortality is observed in the overweight group. Importantly, intentional weight loss was associated with improvement in indices of cardiac structure and myocardial function in obese patients.

Trial registration number APP 74412.

\section{INTRODUCTION}

Obesity is a modern-day epidemic affecting more than one-third of the population worldwide. ${ }^{1}$ Similarly, heart failure (HF) is a major public health problem with an estimated lifetime risk of one in five. Obesity is considered to contribute to the increasing incidence of all subgroups of $\mathrm{HF}^{2}$ However, there have been variable reports on the impact of obesity on HF prognosis. ${ }^{3}$ Though wasting in terminal HF patients has been associated with poor prognosis, a recent bariatric surgery study has shown that intentional weight loss in obese patients is associated with reduced risk of incident $\mathrm{HF}^{45}$ The present ACCF/AHA society guidelines appreciate that obesity is a risk factor for HF but do not have firm recommendations on weight management in $\mathrm{HF}^{6}$

Therefore, a potential beneficial impact of intentional weight loss in obese patients continues to be a issue of conjecture but worth investigating given the benefit observed in other patient populations such as atrial fibrillation (AF)..$^{7}$ The purpose of this systematic review and metaanalysis is to evaluate the relationship between obesity and the incidence of HF and its impact on prognosis in HF in the general population and to explore the impact of intentional weight loss in obese individuals on indices of cardiac structure and function by bariatric surgery.

\section{METHODS}

This systematic review complies with the Metaanalysis of Observational Studies in the Epidemiology group and Preferred Reporting Items for Systematic Review and Meta-Analysis statements. The meta-analysis was registered with PROSPERO International register for systematic reviews (APP 74412).

\section{Search strategy}

The English scientific literature was searched using PubMed, Embase and Web of Science between the period 1 January 1950 to 3 April 2018 with the assistance of an experienced librarian. The following keywords were used 'Obesity', 'abdominal obesity', 'Diabetic Obesity', 'Metabolic Syndrome X', 'Morbid Obesity', body mass index', 'obesity hypoventilation syndrome', 'cardiorenal syndrome', 'congestive heart failure', 'heart failure with preserved ejection fraction', 'diastolic dysfunction' 'heart ventricle failure', 'bariatric surgery', 'intentional weight loss', 'left ventricle', 'left ventricular hypertrophy', 'cardiac hypertrophy', 'natriuretic peptide', 'BNP' and 'NT-BNP'. The details are provided in online supplementary 1 The retrieved references were exported to EndNote X7.3, and duplicate citations were removed. 


\section{Inclusion and exclusion criteria}

The inclusion criteria were: (1) original articles describing the association of obesity and HF; (2) obesity categories defined according to standard guidelines: underweight, normal BMI, overweight and obese defined as BMI $<18.5 \mathrm{~kg} / \mathrm{m}^{2}, 18.5-$ $24.9 \mathrm{~kg} / \mathrm{m}^{2}, \quad 25.0-29.9 \mathrm{~kg} / \mathrm{m}^{2}$ and $\geq 30 \mathrm{~kg} / \mathrm{m}^{2}$, respectively. Severe obesity and morbid obesity were defined as BMI $>35 \mathrm{~kg} / \mathrm{m}^{2}$ and $>40 \mathrm{~kg} / \mathrm{m}^{2}$, respectively; (3) HF defined as per standard definitions such as ICD-9 or ICD-10, Framingham Heart Study Criteria or European Society of Cardiology (ESC) guideline definition. The exclusion criteria were: (1) acute decompensated HF; (2) studies reporting on RV dysfunction only; (3) BMI categories not defined as per standard guidelines; (4) conference abstracts, editorials, reviews, letters and case reports; (5) small sample size (incidence $<5000$ patients; prognosis $<500$ patients and intentional weight loss achieved through bariatric surgery $<50$ patients); (6) HF prognosis studies of 1 year or less in follow-up duration; (7) intentional weight loss studies that recruited patients with HF in selected population with coronary artery disease or AF only; and (8) intentional weight loss studies with inadequate echocardiographic data. The exclusion of intentional weight loss studies that included patients with AF and coronary artery disease was deemed necessary to provide a representative cohort of obese subjects without cardiac conditions that are impacted by intentional weight loss. Where multiple studies described the same population (substudies and follow-up studies), the study with the most comprehensive data was included.

\section{Study selection and data extraction}

The study selection and data extraction were performed by authors (RM and MS), using the predefined inclusion and exclusion criteria. Although review articles were excluded, their reference lists were examined for potential relevant publications. During data extraction, information was collected on the study design, follow-up time, outcome measures, method of assessing outcomes, inclusion/exclusion criteria and results. Where available, the maximally adjusted risk ratios were extracted and pooled across studies. The data were reviewed by two authors independently and disagreements resolved by consensus. The methodological qualities of the included studies were assessed using the Newcastle-Ottawa Scale. The outcomes of the analysis were defined as: (1) incidence of chronic $\mathrm{HF}$ across various BMI categories in general population; (2) effect of BMI on cardiovascular (CV) and all-cause mortality in chronic HF in general population; and (3) impact of intentional weight loss achieved via bariatric surgery in obese individuals on cardiac structure and function.

\section{Statistical analysis}

Continuous variables are presented as the mean or median and categorical variables as $\mathrm{n}(\%)$. Separate meta-analyses were performed for: (1) incidence of chronic HF across various BMI categories; (2) effect of BMI on prognosis in chronic $\mathrm{HF}$; and (3) impact of intentional weight loss on adverse cardiac remodelling and indices of myocardial function in obese individuals. Where meta-analysis was not feasible due to small patient or study numbers, raw results were tabulated. A random effects model, using the DerSimonian \& Laird method, was used to pool data across studies. Meta-analysis was performed using Review Manager V.5.3. Two metaanalytic effects size types were used for the data analyses, namely: standardised mean difference (SMD) and ORs. SMD was used for reporting association with change in indices of myocardial function as some studies reported indexed values, scaled to body size, rather than absolute values. Back transformation was not always possible. The $\mathrm{I}^{2}$ statistic was used as a measure of variability in observed effect estimates attributable to heterogeneity between the studies.

\section{RESULTS}

\section{Search and synthesis of the literature}

The online search of PubMed, Embase and Web of Science from 1 January 1950 to 3 April 2018 yielded 4959 citations. Hand searching of references of reviews did not yield additional citations. Of these, 4794 citations were excluded on primary review as they did not meet the inclusion criteria. One hundred and sixty-five citations were identified for secondary review. After removal of studies with sample size less than defined (in exclusion criteria), reviews and non-relevant articles $(n=98)$, BMI categories not defined according to WHO guidelines, ${ }^{8}$ inadequate data for research questions $(n=29)$ and redundant studies $(n=1), 29$ studies were included in the final analysis. Of these, 9 studies reported on the association of obesity with HF, ${ }^{2-15} 11$ studies reported on the impact of $\mathrm{BMI}$ on prognosis in chronic $\mathrm{HF}^{16-26}$ and 9 studies reported on the impact of intentional weight loss following bariatric surgery on cardiac structure and function. ${ }^{26-34}$ Figure 1 provides the Consolidated Standards of Reporting Trials flow diagram for the data search.

\section{Obesity and incidence of HF}

Nine studies consisting of 375056 patients with mean age $53 \pm 8$ years and follow-up of $12 \pm 6$ years were analysed. $^{29-143536}$ Two of the studies used ESC guideline criteria for HF diagnosis, ${ }^{13} 36$ three of the studies used the Framingham Heart Study criteria for diagnosis ${ }^{211} 12$ and the remaining four studies used ICD-9 and ICD-10 criteria for diagnosis. 9101435 Three studies were in diabetic cohorts. Online supplementary 2 provides the study design and the baseline characteristics of patients in studies assessing the incidence of HF in obesity. Insufficient data on left ventricular ejection fraction (LVEF) was reported in these studies. For each categorical BMI group, the incidence of HF was $0.99,0.34,0.59,1.05$ and 2.79 cases per 100 person-years for the underweight, normal, overweight, obese and morbid obese groups, respectively. The risk of incident HF (reference group: normal BMI) across BMI categories was 1.22 (95\% CI 0.95 to $1.58, \mathrm{p}=0.12)$ ), 1.11 (95\% CI 0.97 to $1.27, \mathrm{p}=0.13), 1.62$ (95\% CI 1.32 to $1.99, \mathrm{p}<0.001)$ and $1.73(95 \%$ CI 1.30 to $2.31, \mathrm{p}<0.001)$ for underweight, overweight, obese and severely obese individuals, respectively (Figures 2,3A). There was evidence of significant heterogeneity among all comparisons other than that for underweight versus normal BMI.

\section{Impact of obesity on CV and all-cause mortality in HF}

Eleven studies, consisting of 41019 patients with mean age $67 \pm 4$ years and follow-up of $4.8 \pm 3.4$ years, were analysed. ${ }^{16-26}$ The HRs for CV mortality (reference group: normal BMI) across BMI categories were 1.20 (95\% CI 0.61 to 2.39, $\mathrm{n}=2$ studies, $\left.{ }^{1623} \mathrm{p}=0.6\right), 0.86(95 \%$ CI 0.79 to 0.94$) ; \mathrm{n}=3$ studies $^{162123} \mathrm{p}=0.001$ ) and 0.97 (95\% CI 0.72 to 1.33 , $\mathrm{n}=4$ studies, ${ }^{16212326} \mathrm{p}=0.87$ ) for underweight, overweight and obese individuals, respectively (Figures 4B,5). The CV mortality was lower in the overweight group relative to normal BMI individuals with absence of significant heterogeneity $\left(\mathrm{I}^{2}=57 \% ; \mathrm{p}=0.10\right)$. However, the $\mathrm{CV}$ mortality was not 

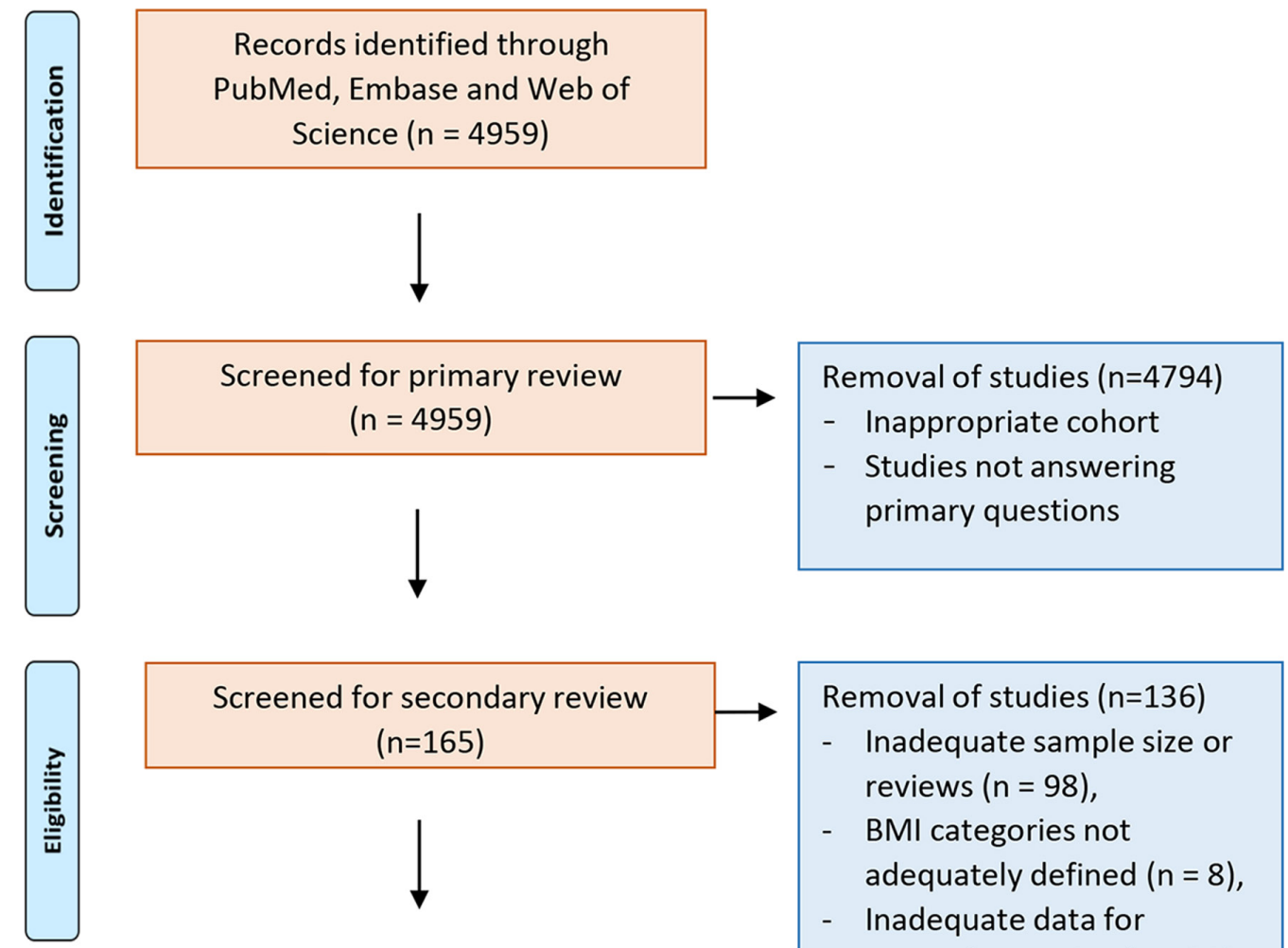

Removal of studies ( $n=136)$

- Inadequate sample size or reviews $(n=98)$,

- BMI categories not

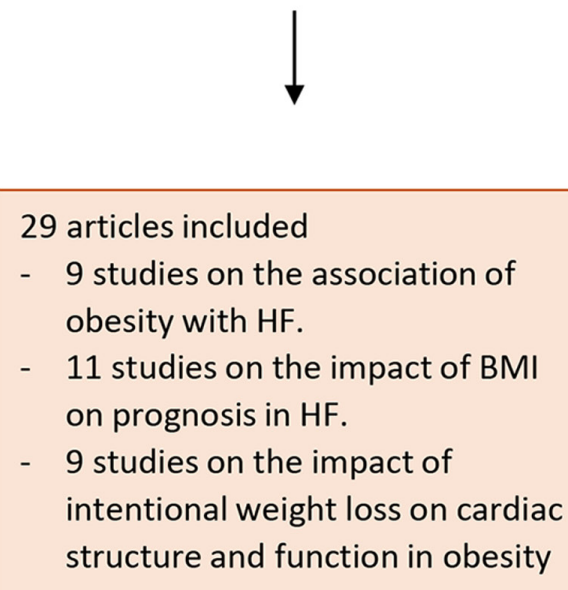
adequately defined $(n=8)$,

- Inadequate data for

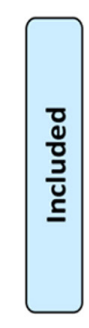
research question $(n=29)$,

- Redundant study $(n=1)$.

Figure 1 Search criteria and flow diagram of the literature selection process. BMI, body mass index; HF, heart failure.

significantly different in the other groups analysed. There was substantial heterogeneity observed in these groups $\left(\mathrm{I}^{2} \geq 79 \%\right.$, $\mathrm{p} \leq 0.03)$. Insufficient data were available to perform a metaanalysis on CV mortality in patients considered severely obese.

Table 1 provides the study design and the baseline characteristics of patients in studies assessing the impact of obesity on all-cause mortality in patients with HF. The risk for allcause mortality was significantly higher in the underweight group with progressive decline in mortality with increase in BMI from underweight to severely obese categories. The HRs for all-cause mortality in HF in underweight, overweight, obese and morbidly obese categories were 1.40 (95\% CI 1.25 to $1.57, \mathrm{n}=4$ studies, ${ }^{16} 1920 \mathrm{p}<0.001$ ), 0.88 (95\% CI 0.79 to $0.98, \mathrm{n}=10$ studies, $\left.{ }^{16-25} \mathrm{p}=0.02\right), 0.80$ (95\% CI 0.69 to $0.91, \mathrm{n}=10$ studies, ${ }^{16-25} \mathrm{p}<0.001$ ) and 0.80 (95\% CI 0.77 to $0.83, \mathrm{n}=2$ studies, $\left.{ }^{20}{ }^{21} \mathrm{p}<0.001\right)$, respectively. There was evidence of statistical heterogeneity among included studies in the overweight and obese analyses $\left(\mathrm{p}<0.001, \mathrm{I}^{2}>90 \%\right)$. Figure 5 shows the forest plots demonstrating the relationship of all-cause mortality to BMI.

\section{Effect of intentional weight loss on cardiac structure and function in obesity}

Nine bariatric surgery studies reported intentional weight loss with a mean reduction in weight of $39.4 \mathrm{~kg}(\mathrm{n}=8 ; 95 \% \mathrm{CI}$ $-45.5 \mathrm{~kg}$ to $-33.4 \mathrm{~kg}$ ) and reduction in BMI by $13.6 \mathrm{~kg} /$ $\mathrm{m}^{2}\left(\mathrm{n}=9 ; 95 \% \mathrm{CI}-15.6 \mathrm{~kg} / \mathrm{m}^{2}\right.$ to $\left.-11.6 \mathrm{~kg} / \mathrm{m}^{2}\right)$ over a mean follow up of $18.1 \pm 15.2$ months. ${ }^{26-34}$ The weight loss surgeries used were gastric bypass, $2622^{29-3133}$ biliopancreatic diversion with duodenal switch, ${ }^{32}$ gastric sleeve, ${ }^{26} 303334$ and vertical banded gastroplasty. ${ }^{33}$ One study did not specify the type of bariatric surgery used. ${ }^{28}$ Intentional weight loss resulted in reduced left ventricular mass index (SMD -0.49 , 95\% CI -0.73 to $-0.26 ; \mathrm{p}<0.0001)$, improvement in diastolic function (E/A- SMD $0.65,95 \%$ CI 0.38 to $0.91 ; \mathrm{p}<0.0001$ ) and reduced left atrial size (SMD $-0.39,95 \%$ CI -0.72 to -0.07 ; $\mathrm{p}=0.02)$. There was also a non-significant improvement in LVEF (SMD 0.43 , 95\% CI 0.00 to 0.86 ; $=0.05$ ). One study compared two different surgical approaches and did not report any difference in outcome. Figure 6 shows the impact of intentional weight loss on cardiac function in obesity. 
A. HF incidence in underweight heart failure patients

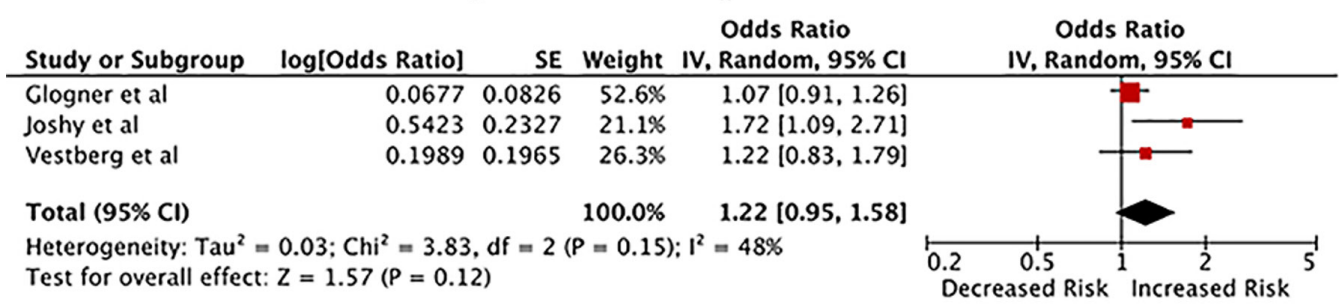

B. HF incidence in overweight heart failure patients.

\begin{tabular}{|c|c|c|c|c|c|c|c|}
\hline Study or Subgroup & log[Odds Ratio] & SE & Weight & $\begin{array}{l}\text { Odds Ratio } \\
\text { IV, Random, } 95 \% \mathrm{Cl}\end{array}$ & $\begin{array}{r}\text { Odds } \\
\text { IV, Randor }\end{array}$ & $\begin{array}{l}\text { Ratio } \\
\mathrm{m}, 95 \% \mathrm{Cl}\end{array}$ & \\
\hline Li et al (Females) & -0.1985 & 0.0955 & $12.3 \%$ & $0.82[0.68,0.99]$ & & & \\
\hline Vestberg et al & -0.0619 & 0.0952 & $12.3 \%$ & $0.94[0.78,1.13]$ & & & \\
\hline Li et al (Males) & -0.0101 & 0.1024 & $11.8 \%$ & $0.99[0.81,1.21]$ & & & \\
\hline Murphy et al & 0.0488 & 0.2526 & $5.1 \%$ & $1.05[0.64,1.72]$ & & & \\
\hline Joshy et al & 0.0488 & 0.1996 & $6.9 \%$ & $1.05[0.71,1.55]$ & & & \\
\hline Glogner et al & 0.1222 & 0.0375 & $15.2 \%$ & $1.13[1.05,1.22]$ & & $=$ & \\
\hline Morkedal et al & 0.1823 & 0.1192 & $10.9 \%$ & $1.20[0.95,1.52]$ & & & \\
\hline Kenchaiah et al (a) & 0.3293 & 0.1102 & $11.4 \%$ & $1.39[1.12,1.73]$ & & - & \\
\hline Kenchaiah et al (b) & 0.3988 & 0.0618 & $14.1 \%$ & $1.49[1.32,1.68]$ & & $\sigma$ & \\
\hline Total $(95 \% \mathrm{Cl})$ & & & $100.0 \%$ & $1.11[0.97,1.27]$ & & & \\
\hline \multicolumn{5}{|c|}{$\begin{array}{l}\text { Heterogeneity: } \mathrm{Tau}^{2}=0.03 ; \mathrm{Chi}^{2}=40.38, \mathrm{df}=8(P<0.00001) ; \mathrm{I}^{2}=80 \% \\
\text { Test for overall effect: } \mathrm{Z}=1.51(P=0.13)\end{array}$} & $\begin{array}{ll}0.2 & 0.5 \\
\text { Decreased Risk }\end{array}$ & ${ }^{1}{ }^{2}$ & \\
\hline
\end{tabular}

C. HF incidence in obese heart failure patients

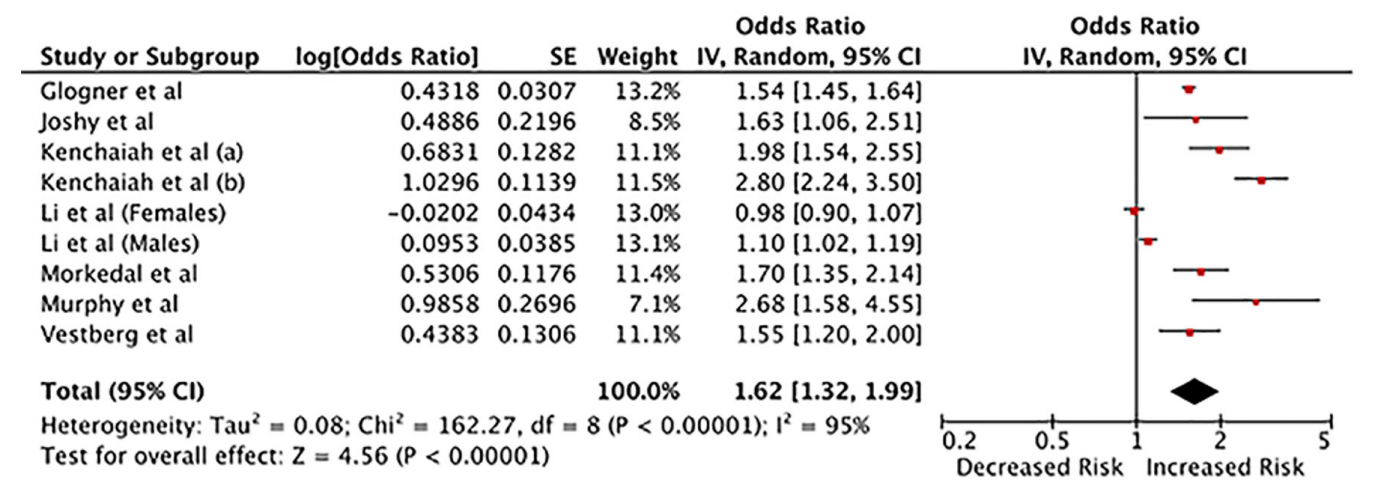

D. HF incidence in morbid obese heart failure patients.

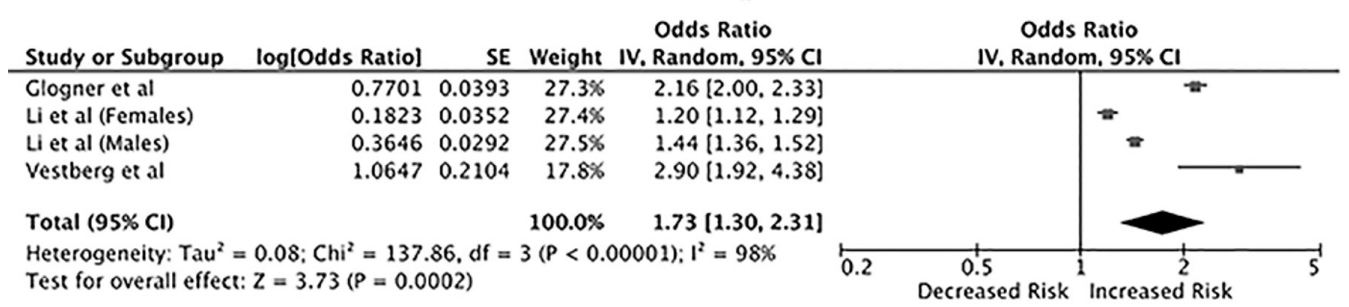

Figure 2 Increased incidence of HF with obesity. Panels A, B, C and D: HF incidence in underweight, overweight, obese and morbid obese patients with heart failure (HF), respectively.

Study quality and the assessment of risk of bias

All included studies were representative of the relevant cohort with adequate sample size. There was low risk of detection and information biases in all studies. Online supplementary tables 3A, 2B,Cprovides the modified Newcastle Ottawa Score for the included studies.

\section{DISCUSSION}

The relationship of obesity with HF is complex with several studies signalling a paradoxical relationship for mortality. The current meta-analysis highlights the increasing risk of HF across the categories of BMI. Despite the higher incidence of HF with obesity, in the presence of established HF, obesity was associated with a paradoxical decline in all-cause mortality. A U-shaped relationship curve was observed between CV mortality and BMI; the overweight cohort experiencing least CV mortality. Importantly, intentional weight loss by bariatric surgery in obese patients resulted in improvement in indices of cardiac structure and myocardial function. The impact of weight loss interventions on clinical outcomes in patients with HF remains unknown. 


\section{A. J shaped relationship of body mass index and heart failure}

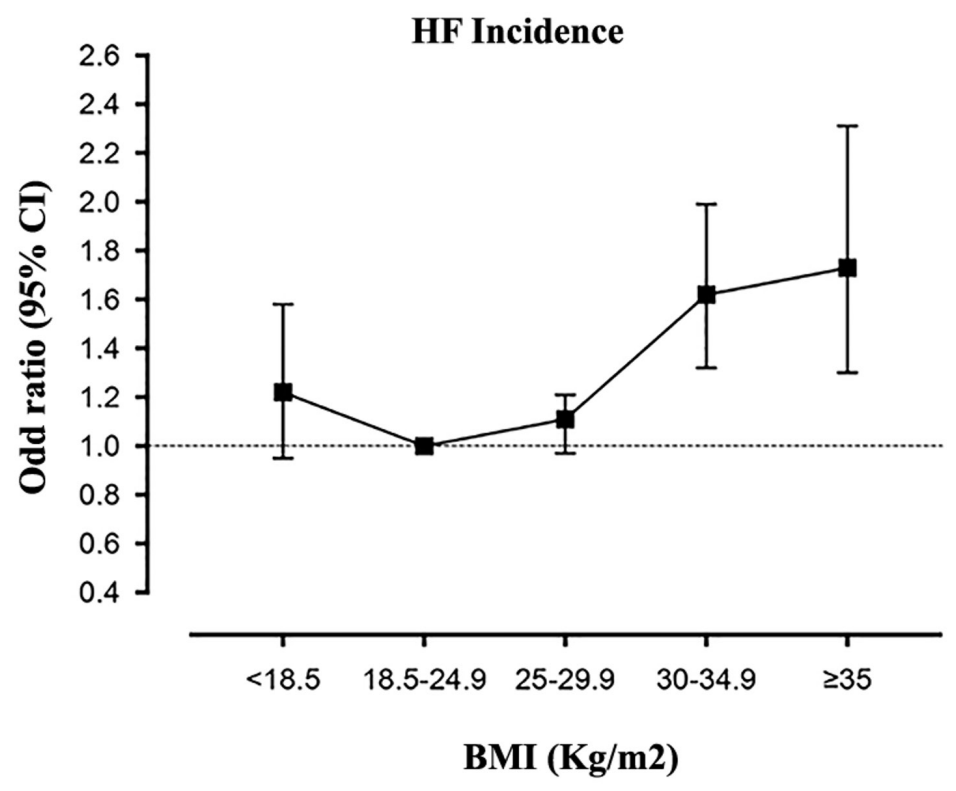

\section{B. Body mass index and cardiovascular mortality in heart failure}

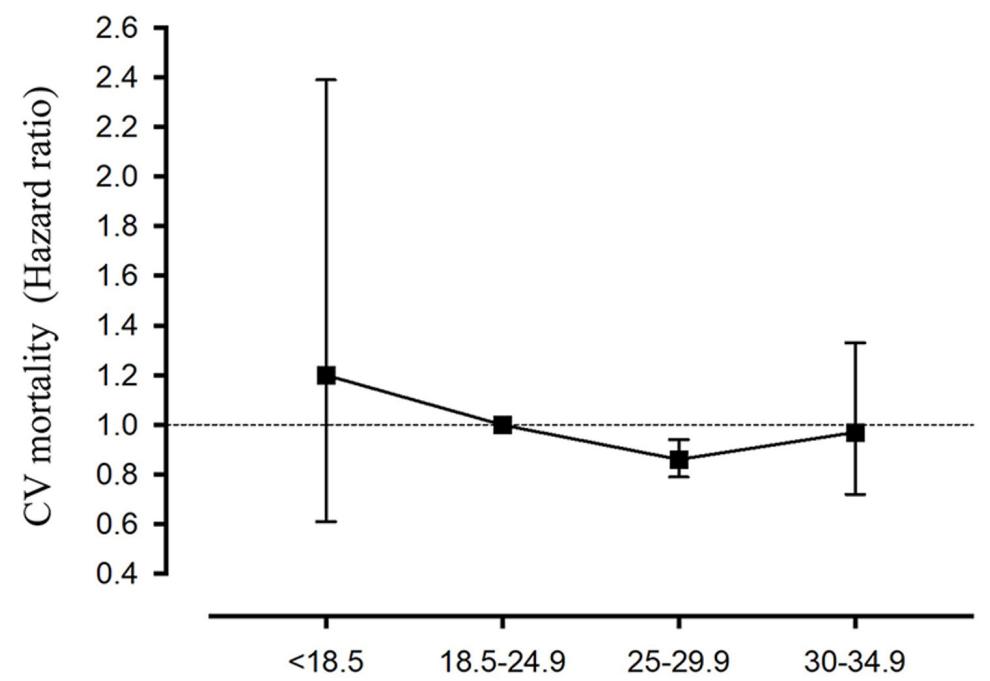

Figure 3 Panel A: J shaped relationship of obesity and HF incidence. Panel B: U shaped relationship of obesity and cardiovascular mortality in HF with nadir shifted to overweight group.

\section{J-curve relationship between obesity and risk of HF}

The current meta-analysis suggests the presence of a 'J-curve' relationship between obesity and the risk of incident HF. While there was non-significant $22 \%$ and $11 \%$ greater risk of incident HF among underweight and overweight participants, respectively, the obese and morbidly obese participants had $62 \%$ and $73 \%$ greater risk of developing HF.

The mechanisms of HF in obesity are multifactorial. Both experimental and clinical studies have demonstrated that obesity leads to increases in cardiac output and in left heart filling pressures, with subsequent left ventricular hypertrophy and cardiac remodelling resulting in diastolic dysfunction. ${ }^{37}$ Although overt systolic dysfunction is uncommon in the absence of other CV disease, subclinical myocardial dysfunction characterised by decreased systolic mitral annular velocities and reduced longitudinal strain are well described in obesity studies. ${ }^{39}$ Obesity is also associated with clustering of incident $\mathrm{CV}$ risk factors that contribute to the development of ischaemic heart disease, which alone represents a significant aetiological burden of HF. Furthermore, the metabolic syndrome and obstructive sleep apnoea that are frequently present in obese individuals may also contribute to adverse left ventricular loading, dilatation and hypertrophy, pulmonary hypertension and subsequently biventricular failure. ${ }^{37} 39$ In addition to abnormal loading conditions, epicardial adipose tissue has been shown to infiltrate the underlying cardiac muscle and produce profibrotic and proinflammatory cytokines leading to cardiac remodelling. ${ }^{38}$ 40 These changes 


\section{A. Cardiovascular mortality in underweight HF patients}

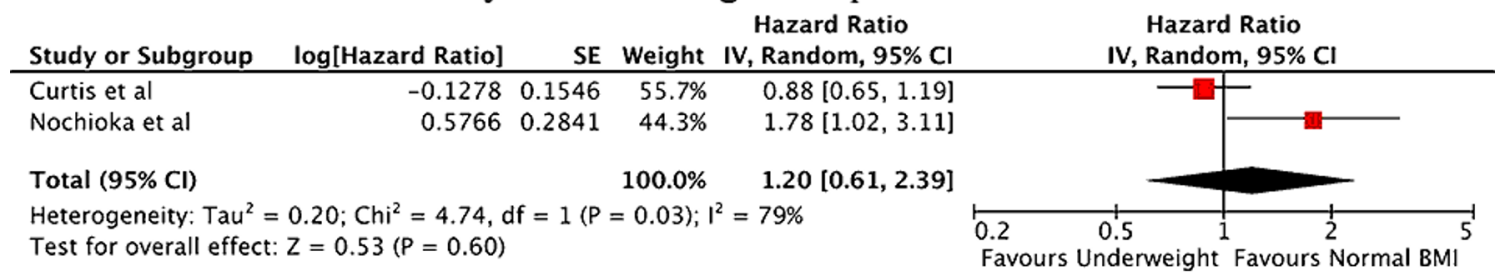

\section{B. Cardiovascular mortality in overweight HF patients}

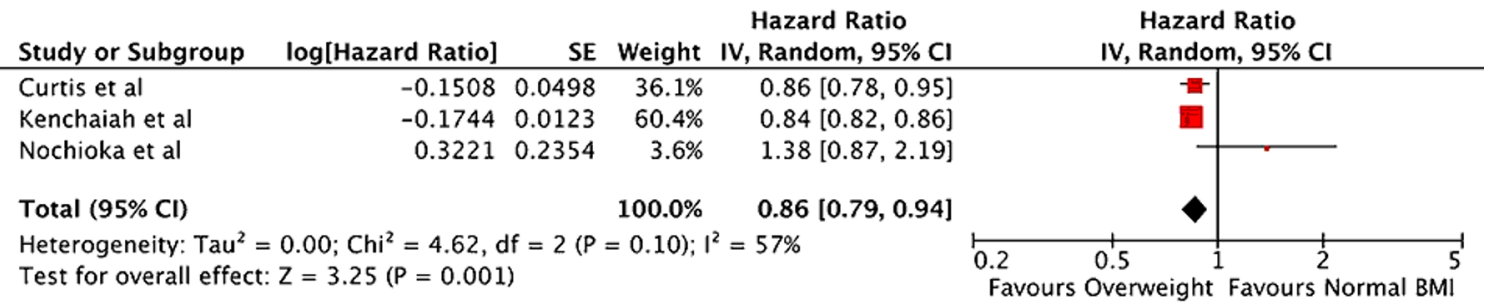

\section{Cardiovascular mortality in obese HF patients}

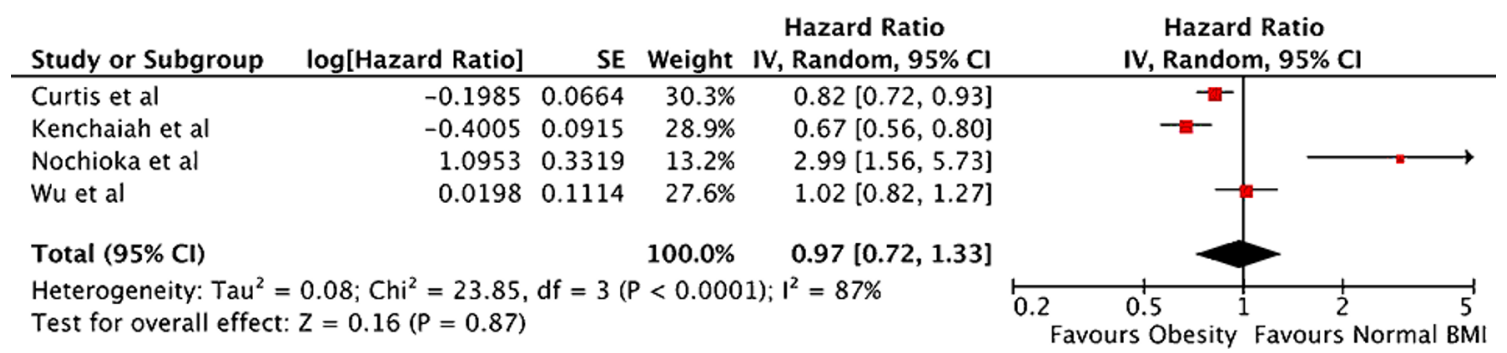

Figure 4 Obesity and cardiovascular mortality. Panel A, B and C: Cardiovascular mortality in underweight, overweight and obese heart failure patients respectively. BMI, body mass index; $\mathrm{CV}$, cardiovascular; $\mathrm{HF}$, heart failure.

develop over several years leading to a steep increase in risk of HF after 10 years of severe obesity. ${ }^{41}$

\section{Obesity paradox in HF: myth or reality}

The obesity paradox has been a long-standing controversy with studies demonstrating lower mortality in obese patients with HF. Horwich et $a l^{3}$ were the first to report the obesity paradox in HF. Further studies have reported best outcomes in the overweight (BMI 25-29.9) or obese (BMI 30-34.9) categories with increasing mortality seen at the extreme ends of the scale. ${ }^{3212342}$ The current meta-analysis confirms the paradoxical decline in all-cause mortality with increasing obesity and demonstrates a U-curve for CV mortality with best outcomes in the overweight group.

The obesity paradox has been attributed to many factors, but the exact mechanisms remain unclear (Box 1). Obese patients may experience greater functional impairment and present early in the course of the disease. ${ }^{16}$ Similarly, older age, lower use of beta-blocker and ACE inhibitors and cardiac cachexia have been reported in low BMI groups. ${ }^{4}$ The obesity paradox has been shown to be eliminated, though inconsistently, when adjustments are made for variables such as age, left ventricular function ${ }^{19}$ and cardiorespiratory reserve. ${ }^{43}$ Criticism of the obesity paradox in HF includes the observation that much of the data which supports this paradox arises from post hoc analysis of clinical trials designed for different purposes, retrospective studies or the analysis of registries arousing concerns of statistical validity and possible unmeasured confounding induced by selection bias. A lead time bias in diagnosis of HF in the obese and a lower specificity of a HF diagnosis in obese individuals may also impact upon prognostic data. Obese patients with HF possess different clinical and epidemiological profiles compared with normal weight patients with HF, which may impact upon mortality. Thus, comparing HF outcomes on BMI may not account for differences in age, aetiology of HF, LVEF, blood pressure, presence of anaemia, diabetes mellitus, renal function and nutritional status where differences are present when comparing obese versus non-obese individuals. ${ }^{44}$

\section{Intentional weight loss in obese HF cohort}

The observation of the obesity paradox in HF has raised scepticism on any potential therapeutic benefit from intentional weight loss in obese patients with HF. However, a recent large Swedish registry has provided robust data on the beneficial effects of intentional weight loss in the prevention of HF development in obese patients. ${ }^{5}$ This study demonstrated a graded decrease in the risk of incident HF with weight loss. A weight loss of $10 \mathrm{~kg}$ was associated with a $23 \%$ lower risk of developing HF. In concurrence with this study, the current meta-analysis showed that intentional weight loss in obesity resulted in improvement in diastolic function and reduction in LV mass as well as left atrial size. This reverse and favourable cardiac remodelling may potentially avert the future development of HF in obesity. The weight loss was achieved with bariatric surgery in the studies included in the meta-analysis. 
A. All-cause mortality in underweight heart failure patients

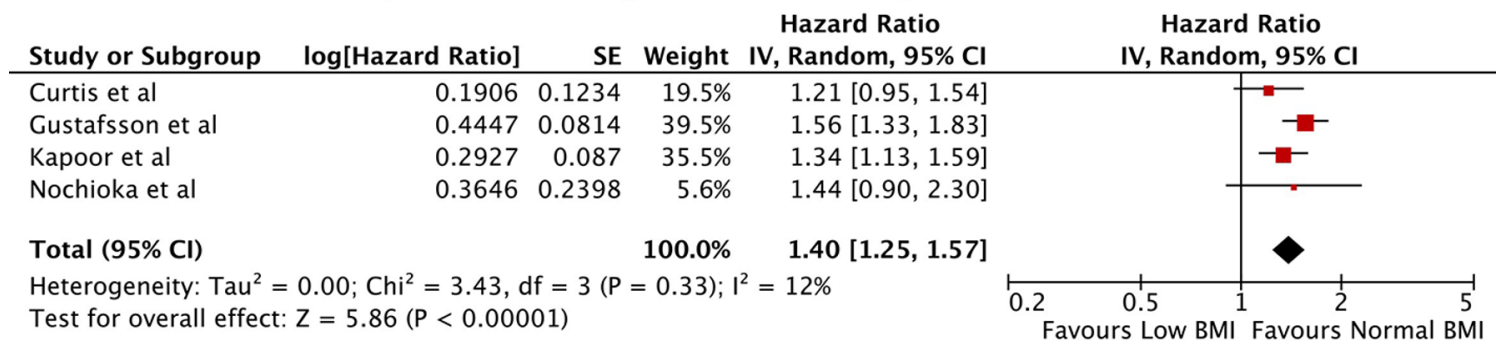

\section{B. All-cause mortality in overweight heart failure patients}

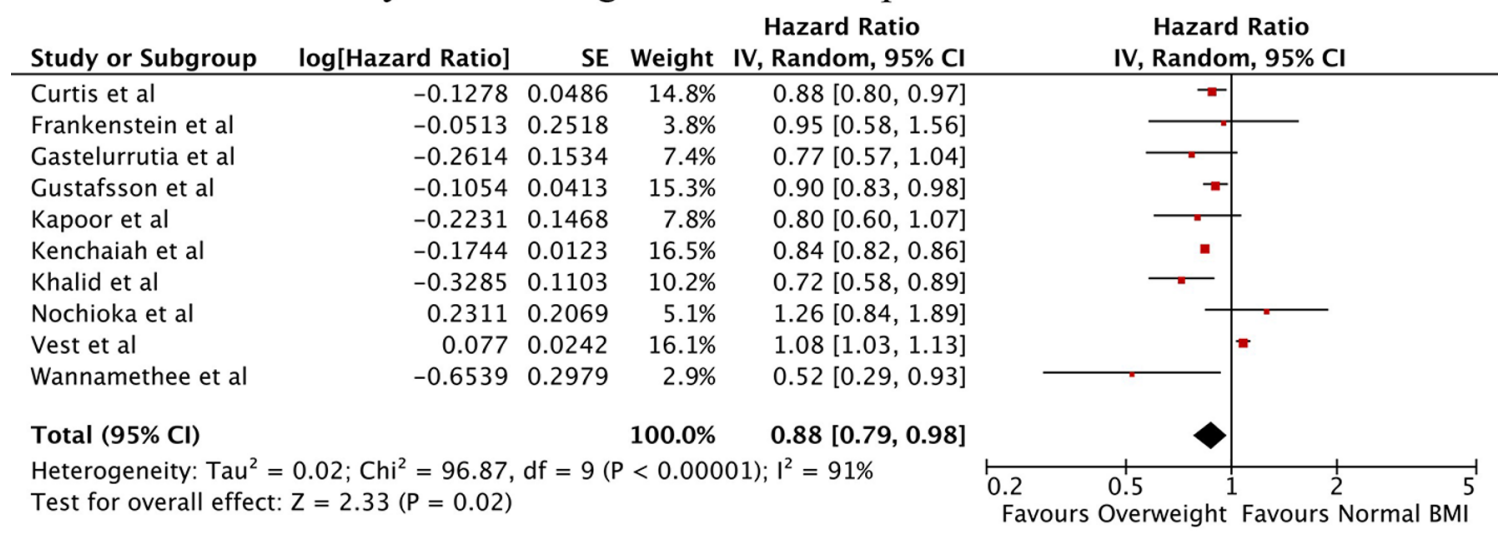

\section{All-cause mortality in obese heart failure patients}

\begin{tabular}{|c|c|c|c|c|c|c|}
\hline \multirow{2}{*}{$\begin{array}{l}\text { Study or Subgroup } \\
\text { Curtis et al }\end{array}$} & log[Hazard Ratio] & SE & Weight & \multirow{2}{*}{$\begin{array}{c}\begin{array}{c}\text { Hazard Ratio } \\
\text { IV, Random, 95\% CI }\end{array} \\
0.81[0.72,0.91]\end{array}$} & \multicolumn{2}{|c|}{$\begin{array}{c}\text { Hazard Ratio } \\
\text { IV, Random, } 95 \% \mathrm{CI}\end{array}$} \\
\hline & -0.2107 & 0.0601 & $13.1 \%$ & & $\varpi$ & \\
\hline Frankenstein et al & -0.3567 & 0.2855 & $4.5 \%$ & $0.70[0.40,1.22]$ & & - \\
\hline Gastelurrutia et al & -0.5276 & 0.1734 & $7.9 \%$ & $0.59[0.42,0.83]$ & - & \\
\hline Gustafsson et al & -0.2614 & 0.0486 & $13.6 \%$ & $0.77[0.70,0.85]$ & $\mp$ & \\
\hline Kapoor et al & -0.2357 & 0.0131 & $14.4 \%$ & $0.79[0.77,0.81]$ & - & \\
\hline Kenchaiah et al & -0.3857 & 0.0812 & $12.2 \%$ & $0.68[0.58,0.80]$ & $\varpi$ & \\
\hline Khalid et al & -0.3567 & 0.1139 & $10.7 \%$ & $0.70[0.56,0.88]$ & & \\
\hline Nochioka et al & 0.2311 & 0.2069 & $6.6 \%$ & $1.26[0.84,1.89]$ & & \\
\hline Vest et al & 0.0862 & 0.024 & $14.2 \%$ & $1.09[1.04,1.14]$ & & $=$ \\
\hline Wannamethee et al & -0.755 & 0.3873 & $2.8 \%$ & $0.47[0.22,1.00]$ & & \\
\hline Total $(95 \% \mathrm{Cl})$ & & & $100.0 \%$ & $0.79[0.69,0.91]$ & & \\
\hline $\begin{array}{l}\text { Heterogeneity: } \mathrm{Tau}^{2} \\
\text { Test for overall effec }\end{array}$ & $\begin{array}{l}.04 ; \mathrm{Chi}^{2}=163.34 \\
=3.22(\mathrm{P}=0.001\end{array}$ & If $=$ & $(P<0.00$ & $001) ; I^{2}=94 \%$ & 0.2 & Favours \\
\hline
\end{tabular}

\section{All-cause mortality in morbidly obese heart failure patients}

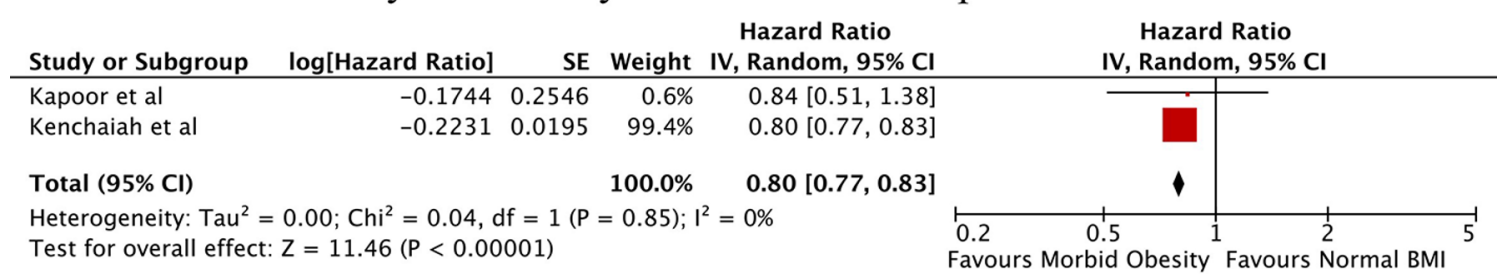

Figure 5 Obesity and all-cause mortality. Panel A, B, C and D: All-cause mortality in underweight, overweight, obese and morbidly-obese heart failure patients respectively.

Notably, there is a striking lack of significant clinical studies on the direct role of intentional weight loss in established $H F$. However, the potential benefit of intentional weight loss as a therapeutic intervention in HF is suggested by a few bariatric surgical studies in patients with HF. First, Vest et al reported retrospective data from 42 patients with left ventricular systolic dysfunction (LVEF $<50 \%$ ) who underwent bariatric surgery with a mean follow-up period of 23 months.
Bariatric surgery resulted in a reduction in BMI of $11 \mathrm{~kg} / \mathrm{m}^{2}$ and a mean LVEF improvement of 5.1\% with no significant cardiac adverse events. ${ }^{45}$ Similarly, improvement in LVEF has been demonstrated in other small case series in obese patients with HF. ${ }^{4647}$ In addition, reduction in HF hospitalisation by intentional weight loss by bariatric surgery has been demonstrated in a recently published self-controlled series of 524 patients with HF and a range of LVEFs. ${ }^{48}$ Intentional weight 
Table 1 Baseline characteristics of patients in studies assessing the impact of obesity on all-cause mortality in heart failure

\begin{tabular}{|c|c|c|c|c|c|c|c|c|c|}
\hline Study & Type of study & $\begin{array}{l}\text { Follow-up } \\
\text { (years) }\end{array}$ & $\begin{array}{l}\text { Gender (\% } \\
\text { male) }\end{array}$ & Age (years) & LVEF (\%) & NYHA & $\begin{array}{l}\text { HF aetiology } \\
\text { ( } \% \text { ischaemic) }\end{array}$ & HTN (\%) & DM (\%) \\
\hline Curtis et $a l^{16}$ & $\mathrm{RCT}$ & 3 & 75.4 & $64 \pm 11$ & $31 \pm 13$ & I-IV & 63.2 & 47.1 & 28.4 \\
\hline Frankenstein et $a l^{18}$ & HF cohort study & 3.4 & $\begin{array}{l}\text { N: } 89 \% . \\
\text { OW: } 89 \% . \\
\text { OB: } 89 \% .\end{array}$ & $\begin{array}{l}\mathrm{N}: 65 \pm 10 \\
\mathrm{OW}: 64 \pm 10 \\
\mathrm{OB}: 63 \pm 10\end{array}$ & $\begin{array}{l}\mathrm{N}: 33 \pm 10 \\
\mathrm{OW}: 31 \pm 10 \\
\mathrm{OB}: 28 \pm 11\end{array}$ & I-III & $\begin{array}{l}\text { N: } 56 \% . \\
\text { OW: } 53 \% . \\
\text { OB: } 57 \% .\end{array}$ & $\begin{array}{l}\text { N: } 33 . \\
\text { OW: } 43 . \\
\text { OB: } 46 .\end{array}$ & $\begin{array}{l}\text { N: } 24 . \\
\text { OW: } 25 . \\
\text { OB: } 28 .\end{array}$ \\
\hline Gastelurrutia et al ${ }^{17}$ & HF cohort study & 3.7 & $\begin{array}{l}\text { N: } 75 \% . \\
\text { OW: } 74 \% . \\
\text { OB: } 69 \% .\end{array}$ & $\begin{array}{l}\mathrm{N}: 64 \pm 13 \\
\text { OW: } 65 \pm 12 \\
\text { OB: } 64 \pm 11\end{array}$ & $\begin{array}{l}\mathrm{N}: 34 \pm 14 \\
\text { OW: } 37 \pm 14 \\
\text { OB: } 40 \pm 14\end{array}$ & II-III & $\begin{array}{l}\text { N: } 48 \% . \\
\text { OW: } 47 \% . \\
\text { OB: } 44 \% .\end{array}$ & $\begin{array}{l}\text { N: } 43 . \\
\text { OW: } 54 . \\
\text { OB: } 70 .\end{array}$ & $\begin{array}{l}\text { N: } 24 . \\
\text { OW: } 38 . \\
\text { OB: } 42 .\end{array}$ \\
\hline Gustafsson et al ${ }^{19}$ & $\begin{array}{l}\text { HF screening } \\
\text { registry }\end{array}$ & 7.5 & $\begin{array}{l}\text { UW: } 31 \% . \\
\text { N: } 56 \% . \\
\text { OW: } 70 \% . \\
\text { OB: } 63 \% .\end{array}$ & $\begin{array}{l}\text { UW: } 76 \text { (58-88). } \\
\text { N: } 74 \text { (56-86). } \\
\text { OW: } 72 \text { (52-85). } \\
\text { OB: } 68 \text { (48-83). }\end{array}$ & NR. & NR. & $\begin{array}{l}\text { UW: } 57 \% . \\
\text { N: } 57 \% . \\
\text { OW: } 60 \% . \\
\text { OB: } 56 \% .\end{array}$ & $\begin{array}{l}\text { UW: } 18 . \\
\text { N: } 21 . \\
\text { OW: } 25 . \\
\text { OB: } 32 .\end{array}$ & $\begin{array}{l}\text { UW: } 8 . \\
\text { N: } 14 . \\
\text { OW: } 17 . \\
\text { OB: } 22 .\end{array}$ \\
\hline $\begin{array}{l}\text { Kapoor and } \\
\text { Heidenreich }\end{array}$ & HF cohort study & 1.2 & $\begin{array}{l}\text { UW: } 98 \% . \\
\text { N: } 95 \% . \\
\text { OW: } 97 \% . \\
\text { OB: } 97 \% . \\
\text { MOB: } 96 \% \text {. }\end{array}$ & $\begin{array}{l}\text { UW: } 75 \pm 13 \\
\text { N: } 76 \pm 11 \\
\text { OW: } 73 \pm 10 \\
\text { OB: } 71 \pm 11 \\
\text { MOB: } 66 \pm 11\end{array}$ & $\begin{array}{l}\text { UW: } 60 \pm 7 \\
\text { N: } 59 \pm 5 . \\
\text { OW: } 60 \pm 5 \\
\text { OB: } 60 \pm 5 \\
\text { MOB: } 59 \pm 5\end{array}$ & NR. & $\begin{array}{l}\text { UW: } 59 \% . \\
\text { N: } 61 \% . \\
\text { OW: } 57 \% . \\
\text { OB: } 64 \% . \\
\text { MOB: } 61 \% \text {. }\end{array}$ & $\begin{array}{l}\text { UW: } 82 \\
\text { N: } 86 \\
\text { OW: } 82 \\
\text { OB: } 89 \\
\text { MOB: } 90\end{array}$ & $\begin{array}{l}\text { UW: } 33 \\
\text { N: } 35 \\
\text { OW: } 37 \\
\text { OB: } 57 \\
\text { MOB: } 66\end{array}$ \\
\hline Kenchaiah et $a l^{21}$ & $\mathrm{RCT}$ & 3.1 & $\begin{array}{l}\text { N: } 70.6 \% . \\
\text { OW: } 73.9 \% . \\
\text { OB: } 66.7 \% . \\
\text { MOB: } 57.9 \% .\end{array}$ & $\begin{array}{l}\text { N: } 68 \pm 10 \\
\text { OW: } 66 \pm 11 \\
\text { OB: } 64 \pm 11 \\
\text { MOB: } 60 \pm 11\end{array}$ & $\begin{array}{l}\text { N: } 37 \pm 14 \\
\text { OW: } 39 \pm 14 \\
\text { OB: } 41 \pm 15 \\
\text { MOB: } 43 \pm 16\end{array}$ & II-IV & $\begin{array}{l}\text { N: } 72 \% . \\
\text { OW: } 74 \% . \\
\text { OB: } 67 \% . \\
\text { MOB: } 56 \% .\end{array}$ & $\begin{array}{l}\text { N: } 41 \\
\text { OW: } 45 \\
\text { OB: } 59 \\
\text { MOB: } 67\end{array}$ & $\begin{array}{l}\text { N: } 21 \\
\text { OW: } 17 \\
\text { OB: } 35 \\
\text { MOB: } 36\end{array}$ \\
\hline Khalid et $a l^{22}$ & HF cohort study & 10 & $\begin{array}{l}\text { N: } 54 \% . \\
\text { OW: } 65 \% . \\
\text { OB: } 45 \% .\end{array}$ & $\begin{array}{l}\mathrm{N}: 67 \pm 6 \\
\text { OW: } 67 \pm 7 \\
\text { OB: } 66 \pm 7\end{array}$ & NR. & NR. & NR. & $\begin{array}{l}\text { N: } 61 \\
\text { OW: } 69 \\
\text { OB: } 77\end{array}$ & $\begin{array}{l}\text { N: } 21 \\
\text { OW: } 36 \\
\text { OB: } 52\end{array}$ \\
\hline Nochioka et $a l^{23}$ & HF cohort study & 3.4 & $\begin{array}{l}\text { UW: } 42 \% . \\
\text { N: } 70 \% . \\
\text { OW: } 73 \% . \\
\text { OB: } 68 \% .\end{array}$ & $\begin{array}{l}\text { UW: } 73 \pm 13 \\
\text { N: } 67 \pm 12 . \\
\text { OW: } 66 \pm 14 \\
\text { OB: } 61 \pm 17\end{array}$ & $\begin{array}{l}\text { UW: } 50 \pm 16 \\
\text { N: } 52 \pm 14 \\
\text { OW: } 53 \pm 16 \\
\text { OB: } 52 \pm 17\end{array}$ & I-IV & $\begin{array}{l}\text { UW: } 33 \% . \\
\text { N: } 23 \% . \\
\text { OW: } 31 \% . \\
\text { OB: } 24 \% .\end{array}$ & $\begin{array}{l}\text { UW: } 46 \\
\text { N: } 49 \\
\text { OW: } 56 \\
\text { OB: } 76 \%\end{array}$ & $\begin{array}{l}\text { UW: } 15 \\
\text { N: } 22 \\
\text { OW: } 25 \\
\text { OB: } 27 \%\end{array}$ \\
\hline Vest et $\left.a\right|^{24}$ & HF cohort study & 6.2 & $\begin{array}{l}\text { N: } 68 \% . \\
\text { OW: } 79 \% . \\
\text { OB: } 75 \% .\end{array}$ & $\begin{array}{l}\text { N: } 55 \pm 13 \\
\text { OW: } 56 \pm 12 \\
\text { OB: } 52 \pm 11\end{array}$ & $\begin{array}{l}\text { N: } 20 . \\
\text { OW: } 20 . \\
\text { OB: } 20 .\end{array}$ & I-IV & $\begin{array}{l}\text { N: } 46 \% . \\
\text { OW: } 51 \% . \\
\text { OB: } 44 \% .\end{array}$ & $\begin{array}{l}\text { N: } 44 \% \\
\text { OW: } 54 \% \\
\text { OB: } 66 \%\end{array}$ & $\begin{array}{l}\text { N: } 17 \% \\
\text { OW: } 26 \% \\
\text { OB: } 38 \%\end{array}$ \\
\hline Wannamethee et $a l^{25}$ & HF cohort study & 11 & $\begin{array}{l}\text { N: } 100 \% . \\
\text { OW: } 100 \% . \\
\text { OB: } 100 \%\end{array}$ & $\begin{array}{l}\text { N: } 72 . \\
\text { OW: } 72 . \\
\text { OB: } 70 .\end{array}$ & NR. & NR. & $\begin{array}{l}\text { N: } 39 \% . \\
\text { OW: } 33 \% . \\
\text { OB: } 61 \% .\end{array}$ & $\begin{array}{l}\mathrm{N}: \\
\text { OW: } \\
\text { OB: }\end{array}$ & $\begin{array}{l}\text { N: } 13 \% \\
\text { OW: } 16 \% \\
\text { OB: } 17 \%\end{array}$ \\
\hline Wu et al & $\mathrm{RCT}$ & 1.4 & $\begin{array}{l}\text { N/OW: } 84 \% . \\
\text { OB: } 73 \% .\end{array}$ & $\begin{array}{l}\text { N/OW: } 64 \pm 12 \\
\text { OB: } 62 \pm 11\end{array}$ & $\begin{array}{l}\text { N/OW: } \\
33 \% \pm 6.1 \% . \\
\text { OB: } \\
33.2 \% \pm 5.9 \% .\end{array}$ & NR. & NR. & $\begin{array}{l}\text { N/OW: } 57 \% \\
\text { OB: } 72 \%\end{array}$ & $\begin{array}{l}\text { N/OW: } 29 \% \\
\text { OB: } 43 \%\end{array}$ \\
\hline
\end{tabular}

BMI, body mass index; HF, heart failure; LVEF, left ventricular ejection fraction; MOB, morbid obesity; N, normal BMI; NR, not reported; NYHA, New York Heart Association; OB, obese; OW, overweight; RCT, randomised controlled trial; UW, underweight.

loss achieved via non-surgical approaches (via caloric restriction and/or aerobic exercise training) has also been found to be beneficial in improving peak oxygen uptake, in patients with HF-PEF. ${ }^{49}$ Similarly, a small study of a 6-month dietary-led interventional weight loss programme in 34 obese chronic HF patients whereby a modest weight loss of $3 \mathrm{~kg}$ was achieved resulted in improvements in functional assessments as well as LVEF. ${ }^{50}$ Further substantial clinical data are required to determine whether weight loss achieved via differing surgical or non-surgical approaches results in differing haemodynamic effects and clinical outcomes in the HF population.

\section{Clinical implications}

Intentional weight loss has been previously shown to be beneficial in obese patients with other $\mathrm{CV}$ disorders such as $\mathrm{AF}^{78}$ The current meta-analysis shows that obesity is associated with HF, and intentional weight loss leads to favourable cardiac remodelling in the obese. It also demonstrates the least CV mortality in HF in the overweight group. Hence, this meta-analysis provides theoretical data with regard to potential prognostic benefit from intentional weight loss in obese patients with HF. This information may be crucial in designing studies to evaluate the role of intentional weight loss in such a cohort.

\section{Limitations}

Although BMI is the most common anthropometric measure of adiposity, it does not accurately distinguish between body fat and lean mass, and the relation between BMI and body fat varies with age, gender and ethnicity. Furthermore, undernutrition may be present in patients classified as obese on the basis of BMI. Despite the limitations, the BMI was the most suitable measure to conduct this meta-analysis. Several studies did not report the aetiology of HF, which is a crucial factor determining prognosis. In addition, the studies did not provide differentiation between $\mathrm{HF}$ with reduced ejection fraction and HF preserved ejection fraction. Furthermore, there were insufficient studies to conduct an analysis for CV mortality in morbidly obese patients with HF. There are also too few studies to draw definite conclusions regarding weight management in HF. Although the bariatric surgery studies provided evidence for improvement in a number of cardiac indices, there was a paucity of information on improvement in outcomes in HF. Finally, the assessment of left atrial size from 


\section{A. Weight loss is associated with reduction in indexed LM Mass}

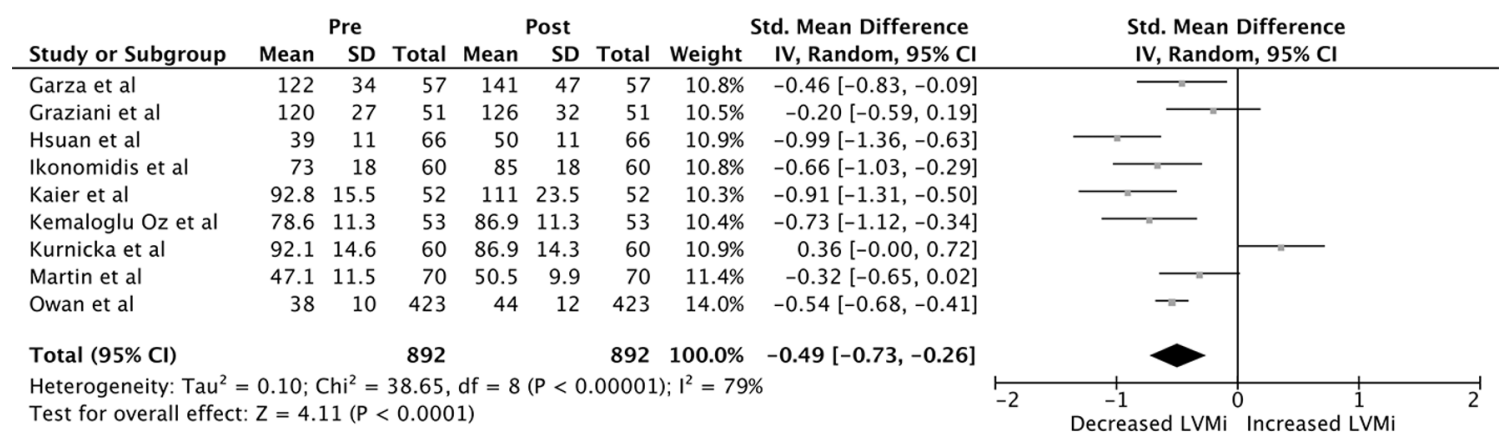

\section{B. Weight loss results in improvement in diastolic dysfuction}

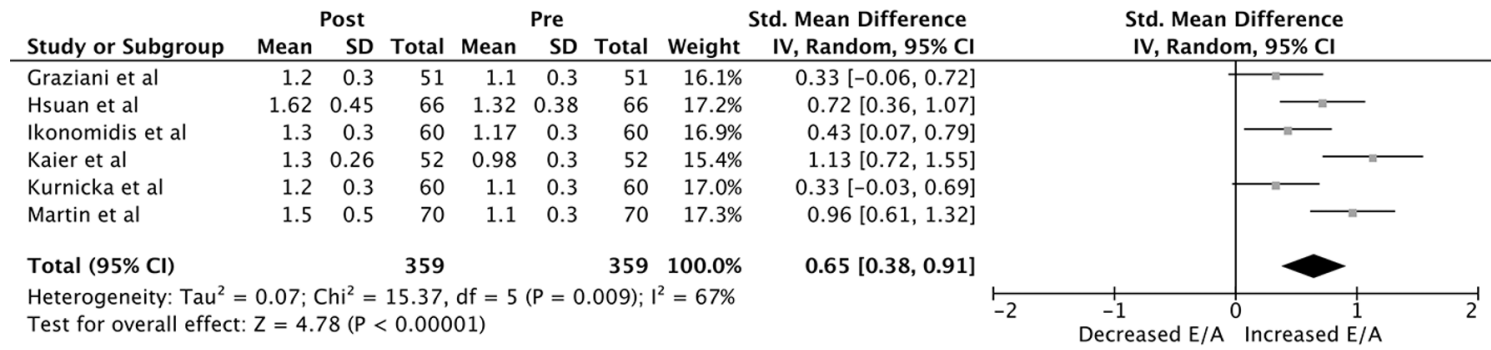

\section{Weight loss results in non-significant improvement in LVEF}

\begin{tabular}{|c|c|c|c|c|c|c|c|c|c|c|c|}
\hline \multirow[b]{2}{*}{ Study or Subgroup } & \multicolumn{3}{|c|}{ Post } & \multicolumn{3}{|c|}{ Pre } & \multicolumn{2}{|r|}{ Std. Mean Difference } & \multirow{2}{*}{\multicolumn{3}{|c|}{$\begin{array}{l}\text { Std. Mean Difference } \\
\text { IV, Random, } 95 \% \mathrm{CI}\end{array}$}} \\
\hline & Mean & SD & Total & Mean & SD & Total & Weight & IV, Random, 95\% Cl & & & \\
\hline Garza et al & 56 & 11 & 57 & 58 & 12 & 57 & $14.2 \%$ & $-0.17[-0.54,0.20]$ & & & \\
\hline Graziani et al & 59 & 4 & 51 & 56 & 5 & 51 & $14.0 \%$ & $0.66[0.26,1.06]$ & & & \\
\hline Kaier et al & 67 & 7 & 52 & 59 & 8 & 52 & $13.9 \%$ & $1.06[0.65,1.47]$ & & & \\
\hline Kemaloglu $\mathrm{Oz}$ et al & 68 & 4.4 & 53 & 60.7 & 4 & 53 & $13.5 \%$ & $1.72[1.28,2.17]$ & & & $\longrightarrow$ \\
\hline Kurnicka et al & 65 & 2 & 60 & 65 & 3 & 60 & $14.3 \%$ & $0.00[-0.36,0.36]$ & & & \\
\hline Martin et al & 62.2 & 6.5 & 70 & 64.6 & 8.1 & 70 & $14.5 \%$ & $-0.33[-0.66,0.01]$ & & & \\
\hline Owan et al & 65 & 8 & 423 & 63 & 11 & 423 & $15.6 \%$ & $0.21[0.07,0.34]$ & & - & \\
\hline Total $(95 \% \mathrm{Cl})$ & & & 766 & & & 766 & $100.0 \%$ & $0.43[0.00,0.86]$ & & & \\
\hline $\begin{array}{l}\text { Heterogeneity: } \mathrm{Tau}^{2} \\
\text { Test for overall effect }\end{array}$ & $\begin{array}{l}0.31 \\
=1\end{array}$ & & $\begin{array}{r}78.87 \\
=0.05\end{array}$ & , $d f=$ & & 0.000 & $01) ; 1^{2}=$ & & $\begin{array}{l}-1 \\
\text { ecreased LVEF }\end{array}$ & $0_{\text {Incre }}$ & $\begin{array}{l}1 \\
\text { LVEF }\end{array}$ \\
\hline
\end{tabular}

\section{Weight loss is associated with reduction in LA size}

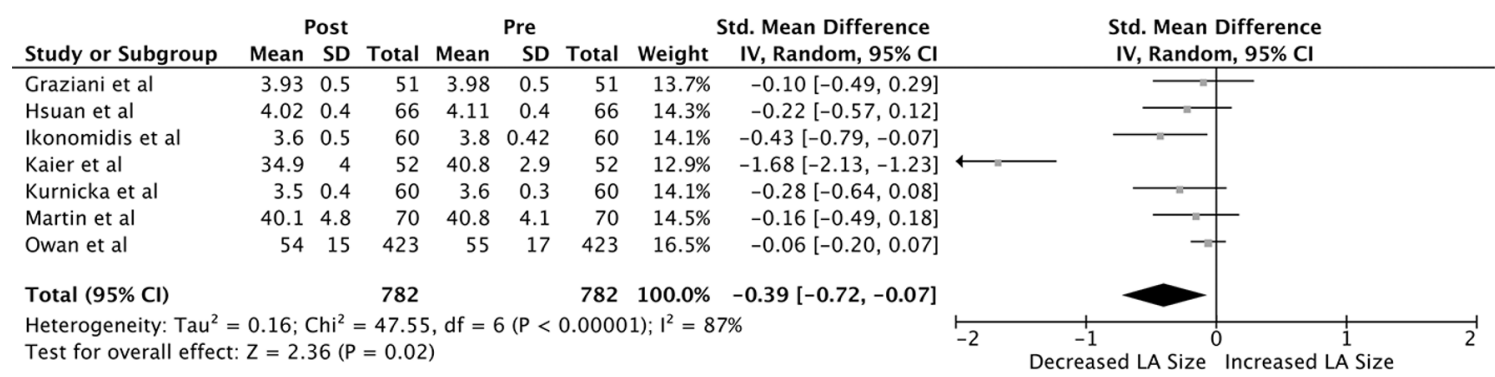

Figure 6 Intentional weight loss leads to favourable adaptive cardiac remodelling. LVEF, left ventricular ejection fraction.

the measurement of a left atrial diameter from the parasternal long-axis imaging was used in the bariatric surgery studies. This measurement, while regularly performed in routine echocardiography, is prone to angulation and foreshortening. It has been essentially superseded by an indexed volumetric assessment (left atrial volume, indexed to body surface area), in echocardiographic laboratories.

\section{CONCLUSION}

Obesity is associated with an increased risk of developing HF. Despite the elevated risk, a paradoxical decline in all-cause mortality is observed. Similarly, a U-shaped curve exists for CV mortality with best outcome evident in the overweight group. Intentional weight reduction results in improvement in indices of cardiac structure and function in obese individuals 
Box 1 Obesity paradox and heart failure

\section{Support of the obesity paradox in heart failure}

- High volume clinical registry data indicating a lower mortality in overweight and mildly obese individuals with heart failure.

- Cardiac cachexia a poor prognostic feature in heart failure.

- Potential protective effects of: tumour necrosis factor-alpha (secreted from adipose tissue).

- Increased tolerability of disease modifying and prognostic pharmacotherapies in the obese.

\section{Controversial aspects and possible explanations obesity} paradox in heart failure

- Lower specificity of heart failure diagnosis in the obese.

- Lead time bias in diagnosis of heart failure in the obese.

- Different clinical and epidemiological profile of heart failure in the obese.

- Statistical validity of large study data, predominantly with body mass index.

- Inherent limitations of body mass index alone as a measure of obesity.

free of HF. Given the burgeoning population incidence of HF, adequately powered and appropriately designed studies to assess the effects of intentional weight loss in obese patients with $\mathrm{HF}$ are urgently required.

\section{Key messages}

What is already known on this subject?

- The management of obesity in heart failure is controversial.

\section{What might this study add?}

- The meta-analysis confirms the increased risk of HF with obesity and presence of an 'obesity paradox' for all-cause mortality. Intentional weight loss improves indices of cardiac function.

\section{How might this impact on clinical practice?}

- Collider stratification bias, lead time bias and different baseline characteristics may explain the obesity paradox. There are no data to suggest detrimental effect of intentional weight loss in obese patients with heart failure. Further studies are required to evaluate the role of intentional weight loss in obese patients with heart failure.

Contributors RM, MS, AE, DL and PS had full access to all the data in the study and take responsibility for the integrity of the data and accuracy of the data analysis. Study concept and design: RM and PS. Acquisition of data: RM and MS. Analysis and interpretation of data: RM, MS, AE, DL and PS. Drafting of manuscript: RM, MS and PS. Critical revision of the manuscript for important intellectual content: all authors. Statistical analysis: RM, MS and AE. Study supervision: RM and PS.

Funding This study was supported by funds from the Centre of Heart Rhythm Disorders at the University of Adelaide. RM is supported by an Early Career Fellowship from the National Health and Medical Research Council (NHMRC) and National Heart Foundation (NHF) of Australia and by the Leo J. Mahar Lectureship by the University of Adelaide. MS is supported by the Dawes Scholarship from the Royal Adelaide Hospital. AE and JH are supported by the Early Career Fellowship from NHF of Australia. DAM is supported by the Robert J. Craig Scholarship from the University of Adelaide and by the Indonesia Endowment Fund for Education, Ministry of Finance, The Republic of Indonesia. KBK is supported by Asia Pacific Heart Rhythm Society and the New Zealand Heart Foundation overseas fellowship. JH is supported by the Derek Frewin Lectureship from the University of Adelaide. DL is supported by a Beacon Research Fellowship from the University of Adelaide. CG is supported a Fellowship from the University of Adelaide. DK is supported by a Senior Research
Fellowship from the NHMRC. DL is supported by the Robert J. Craig Lectureship from the University of Adelaide. PS is supported by Practitioner Fellowships from the NHMRC and by the NHF of Australia. The sponsor of the study is the University of Adelaide. Several of the authors are employees of the University of Adelaide. The sponsor has had no direct involvement in the management or outcomes of the study.

Competing interests The University of Adelaide reports receiving on behalf of RM lecture and/or consulting fees from Abbott and Medtronic. The University of Adelaide reports receiving on behalf of RM research funding from Abbott and Medtronic. DL reports having served on the advisory board of LivaNova and Medtronic. The University of Adelaide reports receiving on behalf of $D L$ reports lecture and/or consulting fees from LivaNova, Medtronic, Pfizer and ResMed. The University of Adelaide reports receiving on behalf of DL research funding from Sanofi, ResMed and Medtronic. PS reports having served on the advisory board of Biosense-Webster, Medtronic, Abbott, Boston Scientific and CathRx. The University of Adelaide reports receiving on behalf of PS lecture and/or consulting fees from Biosense-Webster, Medtronic, Abbott and Boston Scientific. The University of Adelaide reports receiving on behalf of PS research funding from Medtronic, Abbott, Boston Scientific, Biotronik and Liva Nova.

Patient consent for publication Not required.

Provenance and peer review Not commissioned; externally peer reviewed.

Data sharing statement There are no data in this work.

\section{ORCID iDs}

Rajiv Mahajan http://orcid.org/0000-0003-3375-5568

Jeroen Hendriks http://orcid.org/0000-0003-4326-9256

Prashanthan Sanders http://orcid.org/0000-0003-3803-8429

\section{REFERENCES}

1 Ogden CL, Carroll MD, Kit BK, et al. Prevalence of childhood and adult obesity in the United States, 2011-2012. JAMA 2014;311:806-14.

2 Kenchaiah S, Evans JC, Levy D, et al. Obesity and the risk of heart failure. $N$ Engl J Med 2002;347:305-13.

3 Horwich TB, Fonarow GC, Hamilton MA, et al. The relationship between obesity and mortality in patients with heart failure. J Am Coll Cardiol 2001;38:789-95.

4 Anker SD, Ponikowski P, Varney S, et al. Wasting as independent risk factor for mortality in chronic heart failure. Lancet 1997;349:1050-3.

5 Sundström J, Bruze G, Ottosson J, et al. Weight Loss and Heart Failure: A Nationwide Study of Gastric Bypass Surgery Versus Intensive Lifestyle Treatment. Circulation 2017;135:1577-85.

6 Yancy CW, Jessup M, Bozkurt B, et al. 2013 ACCF/AHA guideline for the management of heart failure: executive summary: a report of the American College of Cardiology Foundation/American Heart Association Task Force on practice guidelines. Circulation 2013:128:1810-52

7 Pathak RK, Middeldorp ME, Lau DH, et al. Aggressive risk factor reduction study for atrial fibrillation and implications for the outcome of ablation: the ARREST-AF cohort study. J Am Coll Cardiol 2014;64:2222-31.

8 Mahajan R, Pathak RK, Thiyagarajah A, et al. Risk Factor Management and Atrial Fibrillation Clinics: Saving the Best for Last? Heart Lung Circ 2017;26:990-7.

9 Glogner S, Rosengren A, Olsson M, et al. The association between BMI and hospitalization for heart failure in 83,021 persons with Type 2 diabetes: a population-based study from the Swedish National Diabetes Registry. Diabet Med 2014;31:586-94.

10 Joshy G, Korda RJ, Attia J, et al. Body mass index and incident hospitalisation for cardiovascular disease in 158546 participants from the 45 and Up Study. Int J Obes 2014;38:848-56.

11 Kenchaiah S, Sesso HD, Gaziano JM. Body mass index and vigorous physical activity and the risk of heart failure among men. Circulation 2009;119:44-52.

12 Li W, Katzmarzyk PT, Horswell R, et al. Body mass index and heart failure among patients with type 2 diabetes mellitus. Circ Heart Fail 2015;8:455-63.

13 Mørkedal B, Vatten LJ, Romundstad PR, et al. Risk of myocardial infarction and heart failure among metabolically healthy but obese individuals: HUNT (Nord-Trøndelag Health Study), Norway. J Am Coll Cardio/ 2014:63:1071-8.

14 Murphy NF, MacIntyre K, Stewart S, et al. Long-term cardiovascular consequences of obesity: 20-year follow-up of more than 15000 middle-aged men and women (the Renfrew-Paisley study). Eur Heart J 2006;27:96-106.

15 Vestberg D, Rosengren A, Olsson M, et al. Relationship between overweight and obesity with hospitalization for heart failure in 20,985 patients with type 1 diabetes: a population-based study from the Swedish National Diabetes Registry. Diabetes Care 2013;36:2857-61.

16 Curtis JP, Selter JG, Wang Y, et al. The obesity paradox: body mass index and outcomes in patients with heart failure. Arch Intern Med 2005;165:55-61.

17 Gastelurrutia P, Pascual-Figal D, Vazquez R, et al. Obesity paradox and risk of sudden death in heart failure results from the MUerte Subita en Insuficiencia cardiaca (MUSIC) study. Am Heart J 2011;161:158-64. 
18 Frankenstein L, Zugck C, Nelles M, et al. The obesity paradox in stable chronic heart failure does not persist after matching for indicators of disease severity and confounders. Eur J Heart Fail 2009;11:1189-94.

19 Gustafsson F, Kragelund CB, Torp-Pedersen C, et al. Effect of obesity and being overweight on long-term mortality in congestive heart failure: influence of left ventricular systolic function. Eur Heart J 2005;26:58-64.

20 Kapoor JR, Heidenreich PA. Obesity and survival in patients with heart failure and preserved systolic function: a U-shaped relationship. Am Heart J 2010;159:75-80.

21 Kenchaiah S, Pocock SJ, Wang D, et al. Body mass index and prognosis in patients with chronic heart failure: insights from the Candesartan in Heart failure: Assessment of Reduction in Mortality and morbidity (CHARM) program. Circulation 2007;116:627-36

22 Khalid U, Ather S, Bavishi C, et al. Pre-morbid body mass index and mortality after incident heart failure: the ARIC Study. J Am Coll Cardiol 2014;64:2743-9.

23 Nochioka K, Shiba N, Kohno H, et al. Both high and low body mass indexes are prognostic risks in Japanese patients with chronic heart failure: implications from the CHART study. J Card Fail 2010;16:880-7.

24 Vest AR, Wu Y, Hachamovitch R, et al. The Heart Failure Overweight/Obesity Surviva Paradox: The Missing Sex Link. JACC Heart Fail 2015:3:917-26.

25 Wannamethee SG, Shaper AG, Whincup PH, et al. The obesity paradox in men with coronary heart disease and heart failure: the role of muscle mass and leptin. Int J Cardiol 2014;171:49-55.

26 Hsuan CF, Huang CK, Lin JW, et al. The effect of surgical weight reduction on left ventricular structure and function in severe obesity. Obesity 2010;18:1188-93.

27 Garza CA, Pellikka PA, Somers VK, et al. Structural and functional changes in left and right ventricles after major weight loss following bariatric surgery for morbid obesity. Am J Cardiol 2010;105:550-6.

28 Graziani F, Leone AM, Cialdella P, et al. Effects of bariatric surgery on cardiac remodeling: clinical and pathophysiologic implications. Int J Cardiol 2013;168:4277-9.

29 Ikonomidis I, Mazarakis A, Papadopoulos C, et al. Weight loss after bariatric surgery improves aortic elastic properties and left ventricular function in individuals with morbid obesity: a 3-year follow-up study. J Hypertens 2007;25:439-47.

30 Kaier TE, Morgan D, Grapsa J, et al. Ventricular remodelling post-bariatric surgery: is the type of surgery relevant? A prospective study with 3D speckle tracking. Eur Heart J Cardiovasc Imaging 2014;15:1256-62.

31 Owan T, Avelar E, Morley K, et al. Favorable changes in cardiac geometry and function following gastric bypass surgery: 2-year follow-up in the Utah obesity study. J Am Coll Cardiol 2011:57:732-9.

32 Martin J, Bergeron S, Pibarot $\mathrm{P}$, et al. Impact of bariatric surgery on N-terminal fragment of the prohormone brain natriuretic peptide and left ventricular diastolic function. Can J Cardiol 2013:29:969-75.

33 Kurnicka K, Domienik-Karłowicz J, Lichodziejewska B, et al. Improvement of left ventricular diastolic function and left heart morphology in young women with morbid obesity six months after bariatric surgery. Cardiol J 2018;25.

34 Kemaloğlu Öz T, Ünal Dayı S, Seyit H, et al. The effects of weight loss after sleeve gastrectomy on left ventricular systolic function in men versus women. $J$ Clin Ultrasound 2016:44:492-9.
35 Loehr LR, Rosamond WD, Poole C, et al. The potentially modifiable burden of incident heart failure due to obesity: the atherosclerosis risk in communities study. Am J Epidemiol 2010;172:781-9.

36 Thrainsdottir IS, Aspelund T, Gudnason V, et al. Increasing glucose levels and BMI predict future heart failure experience from the Reykjavík Study. Eur J Heart Fail 2007:9:1051-7.

37 Alpert MA, Karthikeyan K, Abdullah 0, et al. Obesity and Cardiac Remodeling in Adults: Mechanisms and Clinical Implications. Prog Cardiovasc Dis 2018:61:114-23.

38 Mahajan R, Lau DH, Brooks AG, et al. Electrophysiological, Electroanatomical, and Structural Remodeling of the Atria as Consequences of Sustained Obesity. J Am Coll Cardiol 2015;66:1-11.

39 Otto ME, Belohlavek M, Romero-Corral A, et al. Comparison of cardiac structural and functional changes in obese otherwise healthy adults with versus without obstructive sleep apnea. Am J Cardio/ 2007:99:1298-302.

40 Venteclef N, Guglielmi V, Balse E, et al. Human epicardial adipose tissue induces fibrosis of the atrial myocardium through the secretion of adipo-fibrokines. Eur Heart $J$ 2015;36.

41 Alpert MA, Lambert CR, Panayiotou H, et al. Relation of duration of morbid obesity to left ventricular mass, systolic function, and diastolic filling, and effect of weight loss. Am J Cardiol 1995:76:1194-7.

42 Haass M, Kitzman DW, Anand IS, et al. Body mass index and adverse cardiovascular outcomes in heart failure patients with preserved ejection fraction: results from the Irbesartan in Heart Failure with Preserved Ejection Fraction (I-PRESERVE) trial. Circ Heart Fail 2011;4:324-31

43 Piepoli MF, Corrà U, Veglia F, et al. Exercise tolerance can explain the obesity paradox in patients with systolic heart failure: data from the MECKI Score Research Group. Eur J Heart Fail 2016;18:545-53.

44 Guglin M, Baxi K, Schabath M. Anatomy of the obesity paradox in heart failure. Heart Fail Rev 2014:19:621-35.

45 Vest AR, Patel P, Schauer PR, et al. Clinical and Echocardiographic Outcomes After Bariatric Surgery in Obese Patients With Left Ventricular Systolic Dysfunction. Circ Heart Fail 2016;9:e002260.

46 McCloskey CA, Ramani GV, Mathier MA, et al. Bariatric surgery improves cardiac function in morbidly obese patients with severe cardiomyopathy. Surg Obes Relat Dis 2007;3:503-7.

47 Ramani GV, McCloskey C, Ramanathan RC, et al. Safety and efficacy of bariatric surgery in morbidly obese patients with severe systolic heart failure. Clin Cardiol 2008;31:516-20

48 Shimada YJ, Tsugawa Y, Brown DF, et al. Bariatric Surgery and Emergency Department Visits and Hospitalizations for Heart Failure Exacerbation: Population-Based, SelfControlled Series. J Am Coll Cardiol 2016;67:895-903.

49 Kitzman DW, Brubaker P, Morgan T, et al. Effect of Caloric Restriction or Aerobic Exercise Training on Peak Oxygen Consumption and Quality of Life in Obese Older Patients With Heart Failure With Preserved Ejection Fraction. JAMA 2016:315:36-46.

50 Mariotti R, Castrogiovanni F, Canale ML, et al. Weight loss and quality of life in chronic heart failure patients. J Cardiovasc Med 2008:9:576-80. 